\title{
Peripheral leukocyte counts and risk of chlamydia trachomatis (ct), human papilloma viruses (HPV) and cervical disease: a cross-sectional study in a cohort of young women
}

\begin{abstract}
Background: Differential white blood cell (WBC) counts are routinely used as a marker of overall health status as abnormal values can indicate infection, cancer, and other diseases. Recently, differences in WBC within normal ranges have been associated with health outcomes. The human Papilloma virus (HPV) 16/18 vaccine trial in Guanacaste, Costa Rica enrolled 5,711 sexually active healthy women between the ages of 18 and 25 at which time all participants had blood collected for a complete blood count (CBC) as part of a routine clinical assessment.
\end{abstract}

Methods: Using polytomous regression we investigated the associations between circulating leukocyte measures within CBC (granulocytes, lymphocytes, monocytes, total WBC) and chlamydia trachomatis (CT), HPV and HPV-associated low or high squamous intraepithelial lesions (LSIL or HSIL) present at the time of blood collection. Odds ratios (OR) and $95 \%$ confidence intervals $(95 \% \mathrm{CI})$ are presented

Results: Higher lymphocyte counts were associated with a decreased risk of HSIL in women with carcinogenic HPV infection (OR)Lymphocyte high vs. low tertile: 0.62; $95 \%$ CI $(0.43,0.88)$; P-trend $=0.02)$. No significant associations were observed between leukocyte counts and CT status.

Conclusion:The associations we observed between high lymphocyte counts and a decreased prevalence of carcinogenic HPV positive HSIL were significant. Additional studies investigating the role of lymphocyte counts as an indirect risk factor for HPV persistence are needed. In the future, large studies linking peripheral and local leukocyte counts to phenotype and function may identify subsets which are protective from carcinogenic HPV positive HSIL.

Keywords: human papillomavirus, complete blood count, leukocytes, cervical disease
Volume 2 Issue I - 2015

Martha M Sklavos, ' Carolina Porras, ${ }^{2}$

Yuanji Pan Pan,' Nora Macklin Macklin, ${ }^{3}$

Ana Cecilia Rodriquez Rodriquez, ${ }^{2}$ Allan Hildesheim Hildesheim, ${ }^{4}$ Ligia A Pinto Pinto,' Mahboobeh Safaeian Safaeian ${ }^{4}$

'HPV Immunology Laboratory, Frederick National Laboratory for Cancer Research, USA

2Proyecto Epidemiolo gico Guanacaste, Fundacion INCIENSA, Guanacaste, Costa Rica

${ }^{3}$ Center for Disease Control and Prevention, Program

Operations Branch, Puerto Rico

${ }^{4}$ Division of Cancer Epidemiology and Genetics, National

Cancer Institute, USA

Correspondence: Martha M Sklavos, 1050 Boyles Street, Frederick, MD 21702, USA, Tel 4I2-425-4I 38, Fax 301-846-6954, Email Maratha.sklavos@fnlcr.nih.gov

Received: October 03, 2014 | Published: January 02, 2015
Abbreviations: ASCUS, atypical cells of undetermined significance; BMI, body mass index; $\mathrm{CT}$, chlamydia trachomatis; CBC, complete blood count; HPV, human papillomavirus; HSIL, high squamous intraepithelial lesions; LSIL, low squamous intraepithelial lesions; OR, odds ratio; 95\% CI, 95\% confidence intervals; STI, sexually transmitted infections, VLP, virus-like particle; WBC. white blood count

\section{Introduction}

Differential white blood cell (WBC) counts are routinely used as markers of overall health status as abnormal values can indicate infection, cancer, and other diseases. ${ }^{1-5}$ More recently, WBC counts (highest versus lowest quartile) demonstrated a significant association with metabolic syndrome, hyper triglyceridemia, low HDLcholesterol, and high fasting blood glucose. ${ }^{2}$ Several smaller studies categorizing quantitative and qualitative $\mathrm{T}$ cell lymphocyte and other leukocyte measures in women with precancerous cervical lesions or cervical cancer have been performed; however, these studies were small and generated differing conclusions. ${ }^{6-8}$ Normal ranges for $\mathrm{CBC}$ are quite broad with the highest value at the top of the normal range often several fold higher than the lowest value at the bottom of the normal range. ${ }^{9}$ Because normal ranges are so broad, it is also possible that leukocyte count may serve as a crude measure of more subtle differences in the immune system and represent determinants of HPV clearance in healthy individuals.

The current study consists of a community-based population of healthy young adult women enrolled in a bivalent human papillomavirus (HPV) vaccine trial. Because participants were young adults, they were at an age when rates of sexually transmitted infections (STI) tend to peak in many populations. ${ }^{10}$ Accordingly, a high prevalence of STIs were recorded in this population, with HPV and chlamydia trachomatis (CT) being the most prevalent. Thus, we investigated associations between circulating leukocyte counts and current CT infection, HPV infection and HPV-associated cervical lesions.

\section{Materials and methods}

\section{Study Population}

We used data from the Costa Rica Human papillomavirus (HPV) 16/18 vaccine trial (CVT) in Guanacaste, Costa Rica which has been previously described. ${ }^{11}$ In brief, CVT is a community-based doubleblind randomized controlled phase III trial of a virus-like particle (VLP) vaccine against HPV types 16 and 18 . Women were invited to participate based on a census of the young adult female population in the region; the CVT included 7,466 healthy $18-25$ year old women. The 
trial (NCT00128661, ClinicalTrials.gov) was reviewed and approved by the human subjects review committees of INCIENSA (Instituto Costarriciense de Investigacion y Ensenanza en Nutricion y Salud) in Costa Rica and the National Cancer Institute in the United States and all participants signed IRB-approved informed consent forms.

As part of the trial, women were interviewed to obtain information about risk factors related to HPV infection and cervical cancer and a detailed medical history and physical exam were performed by the study clinicians. After eligibility determination, and prior to vaccination, blood for complete blood count $(\mathrm{CBC})$ analysis was collected and a pelvic exam was performed on sexually active participants. The processing of blood samples was performed by Trilab Sci, Liberia and $\mathrm{CBC}$ counts were obtained using the $\mathrm{ABX}$ Micros 60 hematology analyzer (ABX Diagnostics Montpellier, France). During the pelvic exam, exfoliated cells for cytology, HPV DNA and CT DNA were collected in PreservCyt solution. Processing of the PreservCyt vial for preparation of liquid-based, monolayer cytology slides, HPV and CT detection, and processing of the blood samples have been previously described. ${ }^{11}$ Women with cytological evidence of high grade disease or cancer were referred to colposcopy where biopsies were performed for histological diagnosis of HPVassociated squamous intraepithelial lesions.

\section{We defined HPV positivity as}

i. 'Any HPV-positive' if the participant was positive for at least one HPV type.

ii. 'Carcinogenic HPV-positive' if positive for any one of 14 carcinogenic HPV types (HPV 16/18/31/33/35/39/45/51/52/56/5 8/59/66/68_73).

iii. 'Non-carcinogenic HPV-positive' if they were positive for any of the 11 non-carcinogenic HPV types (6/11/34/40/42/43/44/ $53 / 54 / 70 / 74$ ) and not for a carcinogenic type by SPF10-LiPA HPV DNA detection. Cytology was categorized as normal, atypical cells of undetermined significance (ASCUS), low grade squamous intraepithelial lesions (LSIL) or high grade squamous intraepithelial lesions (HSIL), or cancer (no cancers detected at the time of study).

\section{Analysis}

This is a cross-sectional analysis of data and information collected at the study's enrollment visit (prior to vaccination). As sexual experience is a prerequisite for STI exposure only the 5711 nonvirgins, representing approximately two thirds of all enrolled women were included in the current evaluation. We analyzed the association between peripheral lymphocyte, monocyte, granulocyte, and WBC counts and with HPV-positivity at the cervix, CT positivity at the cervix, and cytologically detected ASCUS, LSIL, or HSIL. Leukocyte markers evaluated were checked for distributional properties, and categorized into tertiles of low, medium and high values. Using polytomous logistic regression models, separate analyses were performed for each marker and outcome. All analyses were two-sided. Analyses were performed using SAS and were adjusted for age, body mass index (BMI), smoking, educational grade completed, hormonal contraception, number of sex partners, number of live births, years since first sex, marital status, and CT (for all models except for CT). Women with missing values for any of the $\mathrm{CBC}$ counts or those with missing information for adjustment factors were excluded from the analysis. Odds ratios (OR) and 95\% confidence intervals (95\% CI) were estimated and P-trend analysis was used to assess statistical significance.

\section{Results and discussion}

\section{Results}

In our population of young, healthy, sexually experienced females $(\mathrm{n}=5711), 14 \%$ tested positive for $\mathrm{CT}, 42.1 \%$ tested positive for any type of HPV (non-carcinogenic and/or carcinogenic) and $35.4 \%$ tested positive for at least one type of carcinogenic HPV (Table 1). Overall, HPV-associated lesions were detected in $15.8 \%$ of women. Within this population a wide range of normal values for the immune cell parameters was observed (Table 2).

No significant associations were found between any of the peripheral leukocyte counts measured and CT. We observed some significant associations between leukocyte counts, HPV and HPV-associated lesions. In separate models, we found that higher lymphocytes counts (3rd tertile) were associated with a decreased odds of any type of HPV infection (data not shown) and separately also with decreased odds of any type of lesion (data not shown). Further analysis revealed that these associations were driven mainly by the decreased odds of carcinogenic HPV positive HSIL (OR : $0.62 ; 95 \%$ CI $(0.43,0.88)$; P-trend $=0.02)$ in women with high vs. low tertile
higher lymphocyte counts (Table 3 )

\section{Discussion}

Our results suggest that higher numbers of circulating lymphocytes are associated with decreased incidence of carcinogenic HPV positive HSIL. To our knowledge this study is the first to evaluate the association between peripheral differential leukocyte counts and CT, HPV infection, and HPV-associated disease in a large population of young, healthy, well-characterized women. This suggests that a higher number of circulating lymphocyte counts may be protective from carcinogenic HPV-positive HSIL.

Past studies have demonstrated that lymphocytes appear to be directly involved in clearance of carcinogenic HPV, regression of HPV-associated lesions, and lack of lymph node metastasis in cervical cancer. ${ }^{12}$ If an HPV infection is not adequately controlled and cleared by host lymphocytes, persistent infection and subsequent cervical disease can result. This is most evident in populations of immuno suppressed individuals, who have reduced numbers of lymphocytes resulting from HIV infection or immunosuppressive regimens required by transplantation and thus, are more susceptible to HPVrelated cancers. ${ }^{3,13}$

Presently, aberrant leukocyte counts are used for the diagnosis of various disease states including malignancy and HIV., ${ }^{3,14}$ Leukocyte counts are also used as prognostic markers of survival at the time of diagnosis and often, again, after administration of therapy. ${ }^{5}$ Even though carcinogenic HPV infection and lesions are largely silent disease states, devoid of signs or symptoms of systemic infection, differences in circulating leukocyte counts and more specifically, in lymphocyte counts, may be determinants of disease progression and act as correlates of HPV immunity.

We did not find any associations between leukocyte counts and the presence of CT infection. CT and HPV both require cell-mediated immunity for pathogen clearance, though systemic leukocyte counts were not associated with the presence of CT infection. This observation could indicate that the respective bacterial and viral pathogens have different determinants of infection or indicate that our HPV-associated findings are spurious. Our study has additional limitations. This study only includes rudimentary categories of leukocytes, which lack phenotypic or functional resolution. Lastly, this study was cross-sectional in design; a future longitudinal study would allow adjustment for changes within an individual's leukocyte counts over time. 
Table I Demographic information for study participants

\begin{tabular}{|c|c|c|}
\hline Demographic Table & Number of Participants & Percent \\
\hline Total number of participants & 5706 & $100 \%$ \\
\hline \multicolumn{3}{|l|}{ Enrollment Age } \\
\hline $18-19$ & 1470 & 25.8 \\
\hline $20-22$ & $217 \mid$ & 38.1 \\
\hline $23-25$ & 2065 & 36.2 \\
\hline \multicolumn{3}{|l|}{ Education Completed } \\
\hline Primary school & 1799 & 31.5 \\
\hline Secondary school & 2922 & 51.2 \\
\hline More than secondary school & 985 & 17.3 \\
\hline \multicolumn{3}{|l|}{ Smoking } \\
\hline No (never) & 4802 & 84.2 \\
\hline Former & 537 & 9.4 \\
\hline Current & 367 & 6.4 \\
\hline \multicolumn{3}{|l|}{ Marital Status } \\
\hline Single & 2525 & 44.3 \\
\hline Married/living as married & 2999 & 52.6 \\
\hline Divorced/separated & 182 & 3.2 \\
\hline \multicolumn{3}{|l|}{ Hormonal Contraception (current) } \\
\hline No, $<6$ months & 2322 & 18.1 \\
\hline Yes, 6-36 months & 2349 & 41.2 \\
\hline Yes, >36 months & 1035 & 18.1 \\
\hline \multicolumn{3}{|l|}{ Live Births } \\
\hline 0 & 2424 & 42.5 \\
\hline 2-Jan & 3014 & 52.8 \\
\hline $3+$ & 268 & 4.7 \\
\hline \multicolumn{3}{|l|}{ Number of lifetime sexual partners } \\
\hline $\mathrm{I}$ & 2420 & 42.4 \\
\hline 2 & 1492 & 26.1 \\
\hline 3 & 866 & 15.2 \\
\hline $4+$ & 928 & 16.3 \\
\hline \multicolumn{3}{|l|}{ Years since first sex } \\
\hline $0-1$ & 691 & 12.1 \\
\hline 4-Feb & 2181 & 38.2 \\
\hline $5+$ & 2834 & 49.7 \\
\hline \multicolumn{3}{|l|}{ HPV* } \\
\hline HPV negative (all HPV) & 3283 & 57.9 \\
\hline HPV positive (non-carcinogenic types only) & 381 & 6.7 \\
\hline HPV positive (carcinogenic types $+/$ - non-carcinogenic types) & 2011 & 35.4 \\
\hline \multicolumn{3}{|l|}{ Cytology* } \\
\hline No pathology & 4778 & 84.2 \\
\hline$\leq \mathrm{LSIL}$ & 802 & 14.1 \\
\hline$\geq \mathrm{HSIL}$ & 95 & 1.7 \\
\hline \multicolumn{3}{|l|}{ Current Chlamydia status** } \\
\hline No & 4869 & 86 \\
\hline Yes & 793 & 14 \\
\hline
\end{tabular}

$* N=5675$ and $* * N=5662$ due to missing values; $\leq$ LSIL includes ASCUS and LSIL

CT: Chlamydia Trachomatis; HPV: Human papillomavirus; HSIL: High Squamous Intraepithelial Lesions; LSIL: Low Squamous Intraepithelial Lesions

Table 2 Summary description of the various markers evaluated

\begin{tabular}{lll}
\hline Demographic Table & Number of Participants & Percent \\
\hline Total number of participants & 5706 & \\
Enrollment Age & $100 \%$ \\
$18-19$ & 2170 \\
$20-22$ & 2065 \\
$23-25$ & & 38.1 \\
Education Completed & 1799 \\
Primary school & 36.2 \\
\hline
\end{tabular}

Citation: Sklavos MM, Porras C, Pan YP, et al. Peripheral leukocyte counts and risk of chlamydia trachomatis (ct), human papilloma viruses (HPV) and cervical disease: a cross-sectional study in a cohort of young women. MOJ Immunol. 20I 5;2(I): I-6. DOI: I0.15406/moji.20I5.02.0003 I 
Table Continued.

\begin{tabular}{|c|c|c|}
\hline Demographic Table & Number of Participants & Percent \\
\hline Secondary school & 2922 & 51.2 \\
\hline More than secondary school & 985 & 17.3 \\
\hline \multicolumn{3}{|l|}{ Smoking } \\
\hline No (never) & 4802 & 84.2 \\
\hline Former & 537 & 9.4 \\
\hline Current & 367 & 6.4 \\
\hline \multicolumn{3}{|l|}{ Marital Status } \\
\hline Single & 2525 & 44.3 \\
\hline Married/living as married & 2999 & 52.6 \\
\hline Divorced/separated & 182 & 3.2 \\
\hline \multicolumn{3}{|l|}{ Hormonal Contraception (current) } \\
\hline No, $<6$ months & 2322 & 18.1 \\
\hline Yes, 6-36 months & 2349 & 41.2 \\
\hline Yes, $>36$ months & 1035 & 18.1 \\
\hline \multicolumn{3}{|l|}{ Live Births } \\
\hline 0 & 2424 & 42.5 \\
\hline 2-Jan & 3014 & 52.8 \\
\hline $3+$ & 268 & 4.7 \\
\hline \multicolumn{3}{|l|}{ Number of lifetime sexual partners } \\
\hline I & 2420 & 42.4 \\
\hline 2 & 1492 & 26.1 \\
\hline 3 & 866 & 15.2 \\
\hline $4+$ & 928 & 16.3 \\
\hline \multicolumn{3}{|l|}{ Years since first sex } \\
\hline $0-1$ & 691 & 12.1 \\
\hline 4-Feb & 2181 & 38.2 \\
\hline $5+$ & 2834 & 49.7 \\
\hline \multicolumn{3}{|l|}{$\mathrm{HPV}^{*}$} \\
\hline HPV negative (all HPV) & 3283 & 57.9 \\
\hline HPV positive (non-carcinogenic types only) & 381 & 6.7 \\
\hline HPV positive (carcinogenic types +/- non-carcinogenic types) & 2011 & 35.4 \\
\hline \multicolumn{3}{|l|}{ Cytology* } \\
\hline No pathology & 4778 & 84.2 \\
\hline$\leq$ LSIL & 802 & 14.1 \\
\hline$\geq \mathrm{HSIL}$ & 95 & 1.7 \\
\hline \multicolumn{3}{|l|}{ Current Chlamydia status** } \\
\hline No & 4869 & 86 \\
\hline Yes & 793 & 14 \\
\hline
\end{tabular}

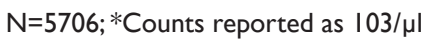

WBC:White Blood Count

Table 3 N=5695 for HPV Outcome; N=5675 for Cytology; N=5662 for Chlamydia status;All models adjusted for age, BMI, smoking, education, hormonal birth control, number of sex partners, number of live births, chlamydia (not in Chlamydia model), marital status, years since first sex; reference category is the lowest tertile of the respective markers; $\leq$ LSIL includes ASCUS and LSIL

\begin{tabular}{|c|c|c|c|c|c|c|c|}
\hline \multirow[t]{2}{*}{ Granulocytes } & \multirow{2}{*}{$\begin{array}{l}\text { Ist tertile } \\
\mathbf{N}\end{array}$} & \multicolumn{3}{|c|}{ 2nd tertile } & \multicolumn{2}{|c|}{ 3rd tertile } & \multirow{2}{*}{$\begin{array}{l}\text { P-trend } \\
\text { adjusted OR }\end{array}$} \\
\hline & & $\mathbf{N}$ & crude OR & adjusted OR & $\mathbf{N}$ & crude OR & \\
\hline HPV Negative & 1089 & 1065 & I & I & 1148 & I & 0.35 \\
\hline Non-carcinogenic HPV & 126 & 112 & 0.91 & $0.91(0.70,1.20)$ & 144 & 1.08 & I.II $(0.86,1.45)$ \\
\hline \multicolumn{8}{|l|}{ Carcinogenic HPV } \\
\hline$\leq$ LSIL & 562 & 627 & 1.14 & $\mathrm{I} .14(0.98,1.33)$ & 616 & 1.04 & $1.09(0.94,1.27)$ \\
\hline$\geq \mathrm{HSIL}$ & 77 & 73 & 0.97 & $0.99(.07 \mathrm{I}, \mathrm{I} .38)$ & 56 & 0.69 & $0.77(0.53,1.10)$ \\
\hline \multicolumn{8}{|l|}{ Chlamydia status } \\
\hline No Chlamydia & |59| & 1603 & I & 1 & 1675 & I & 0.44 \\
\hline Current Chlamydia & 249 & 261 & 1.04 & $1.04(0.86,1.26)$ & 283 & 1.08 & I.II $(0.92,1.35)$ \\
\hline \multirow[t]{2}{*}{ Lymphocytes } & Ist tertile & \multicolumn{3}{|c|}{ 2nd tertile } & \multicolumn{2}{|c|}{$3 r d$ tertile } & P-trend \\
\hline & $\mathrm{N}$ & $\mathrm{N}$ & crude OR & adjusted OR & $\mathrm{N}$ & crude OR & adjusted OR \\
\hline HPV Negative & 842 & 1152 & I & 1 & 1308 & I & 0.02 \\
\hline Non-carcinogenic HPV & 122 & 118 & 0.71 & $0.72(0.55,0.95)$ & $14 \mid$ & 0.74 & $0.80(0.61,1.05)$ \\
\hline Carcinogenic HPV & & & & & & & \\
\hline
\end{tabular}

Citation: Sklavos MM, Porras C, Pan YP, et al. Peripheral leukocyte counts and risk of chlamydia trachomatis (ct), human papilloma viruses (HPV) and cervical disease: a cross-sectional study in a cohort of young women. MOJ Immunol. 20I 5;2(I): I-6. DOI: I0.15406/moji.20I5.02.0003 I 
Table Continued...

\begin{tabular}{|c|c|c|c|c|c|c|c|}
\hline \multirow[t]{2}{*}{ Granulocytes } & \multirow{2}{*}{$\begin{array}{l}\text { Ist tertile } \\
\mathbf{N}\end{array}$} & \multicolumn{3}{|c|}{ 2nd tertile } & \multicolumn{2}{|c|}{ 3rd tertile } & \multirow{2}{*}{$\begin{array}{l}\text { P-trend } \\
\text { adjusted OR }\end{array}$} \\
\hline & & $\mathbf{N}$ & crude OR & adjusted OR & $\mathbf{N}$ & crude OR & \\
\hline$\leq \mathrm{LSIL}$ & 514 & 661 & 0.94 & $0.95(0.8 \mathrm{I}, \mathrm{I} . \mathrm{II})$ & 630 & 0.79 & $0.87(0.75,1.02)$ \\
\hline$\geq \mathrm{HSIL}$ & 70 & 71 & 0.74 & $0.7 \mathrm{I}(0.50,1.01)$ & 65 & 0.6 & $0.62(0.43,0.88)$ \\
\hline \multicolumn{8}{|l|}{ Chlamydia status } \\
\hline No Chlamydia & 1327 & 1698 & I & I & 1844 & I & 0.83 \\
\hline Current Chlamydia & 212 & 291 & 1.07 & $\mathrm{I} .05(0.86, \mathrm{I} .27)$ & 290 & 0.98 & $0.99(0.82,1.21)$ \\
\hline
\end{tabular}

ASCUS: Atypical Cells Of Undetermined Significance; BMI: Body Mass Index; CT: Chlamydia Trachomatis; HPV: Human papillomavirus; HSIL: High Squamous Intraepithelial Lesions; LSIL: Low Squamous Intraepithelial Lesions; OR: Odds Ratio Table 3 (continued) Multivariate association of Chlamydia trachomatis, HPV and Cytology with peripheral leukocyte markers

Table $4 \mathrm{~N}=5695$ for HPV Outcome; $\mathrm{N}=5675$ for Cytology; $\mathrm{N}=5662$ for Chlamydia status;All models adjusted for age, BMI, smoking, education, hormonal birth control, number of sex partners, number of live births, chlamydia (not in Chlamydia model), marital status, years since first sex; reference category is the lowest tertile of the respective markers; SLSIL includes ASCUS and LSIL ASCUS: Atypical Cells Of Undetermined Significance; BMI: Body Mass Index; CT: Chlamydia Trachomatis; HPV: Human papillomavirus; HSIL: High Squamous Intraepithelial Lesions; LSIL: Low Squamous Intraepithelial Lesions; OR: Odds Ratio

\begin{tabular}{|c|c|c|c|c|c|c|c|}
\hline \multirow[t]{2}{*}{ Monocytes } & \multirow{2}{*}{$\begin{array}{l}\text { Ist tertile } \\
\mathbf{N}\end{array}$} & \multicolumn{3}{|c|}{ 2nd tertile } & \multicolumn{2}{|c|}{ 3rd tertile } & \multirow{2}{*}{$\begin{array}{l}\text { P-trend } \\
\text { adjusted OR }\end{array}$} \\
\hline & & $\mathbf{N}$ & crude OR & adjusted OR & $\mathbf{N}$ & crude OR & \\
\hline \multicolumn{8}{|l|}{ Outcome } \\
\hline HPV Negative & 586 & 873 & I & I & 1843 & I & 0.73 \\
\hline Non-carcinogenic HPV & 65 & 99 & 1.02 & I.04 $(0.75, \mathrm{I} .46)$ & 218 & 1.07 & I.II $(0.83$, I.50) \\
\hline \multicolumn{8}{|l|}{ Carcinogenic HPV } \\
\hline$\leq \mathrm{LSIL}$ & 341 & 461 & 0.91 & $0.93(0.77, I .12)$ & 1003 & 0.93 & I $(0.85,|| 8)$. \\
\hline$\geq \mathrm{HSIL}$ & 35 & 57 & 1.09 & I.I $2(0.72$, I.73) & 114 & $\mathrm{I} .04$ & I.IO (0.74, I.64) \\
\hline \multicolumn{8}{|l|}{ Chlamydia status } \\
\hline No Chlamydia & 890 & 1292 & I & I & 2687 & $\mathrm{I}$ & 0.09 \\
\hline Current Chlamydia & 134 & 190 & 0.98 & $0.98(0.77, \mathrm{I} .24)$ & 469 & 1.16 & I.I8 (0.95, I.46) \\
\hline \multirow[t]{2}{*}{ WBC } & Ist tertile & \multicolumn{3}{|c|}{ 2nd tertile } & \multicolumn{2}{|c|}{$3 r d$ tertile } & P-trend \\
\hline & $\mathrm{N}$ & $N$ & crude OR & adjusted OR & $\mathrm{N}$ & crude OR & adjusted OR \\
\hline \multicolumn{8}{|l|}{ Outcome } \\
\hline HPV Negative & 1030 & 1106 & $\mathrm{I}$ & $\mathrm{I}$ & 1166 & I & 0.51 \\
\hline Non-carcinogenic HPV & 123 & 123 & 0.93 & $0.94(0.72, \mathrm{I} .23)$ & 136 & 0.98 & I.03 (0.79, I.35) \\
\hline \multicolumn{8}{|l|}{ Carcinogenic HPV } \\
\hline$\leq \mathrm{LSIL}$ & 578 & 581 & 0.94 & $0.95(0.82, \mathrm{I} . \mathrm{II})$ & 646 & 0.99 & I.08 (0.93, I.26) \\
\hline$\geq \mathrm{HSIL}$ & 80 & 71 & 0.83 & $0.82(0.59,1.15)$ & 55 & 0.61 & $0.68(0.47,0.98)$ \\
\hline \multicolumn{8}{|l|}{ Chlamydia status } \\
\hline No Chlamydia & 1547 & 1623 & I & I & 1699 & I & 0.1 \\
\hline Current Chlamydia & 248 & 248 & 0.95 & $0.93(0.77, \mathrm{I} .13)$ & 297 & 1.09 & I.I $3(0.94$, I.37) \\
\hline
\end{tabular}

\section{Conclusion}

Differential CBC counts as an indicator of disease risk warrants replication and further exploration of lymphocyte subsets in HPV infection and cervical disease. Comparison of the localized and systemic immune response to infection is likely to be fruitful. ${ }^{15}$ as analyses of the infiltrate of leukocytes and other immune cells at the cervix during the progression of persistent carcinogenic HPV infection may better identify characteristics of protective and permissive immune responses in HPV-associated cervical disease.

\section{Acknowledgments}

None.

\section{Conflicts of interest}

Author declares there are no conflicts of interest.

\section{Funding}

None.

\section{References}

1. Andrews JM, Cruser DL, Myers JB, et al. Using peripheral smear review, age and absolute lymphocyte count as predictors of abnormal peripheral blood lymphocytoses diagnosed by flow cytometry. Leuk Lymphoma . 2008;49(9):1731-1737.

2. Babio N, Ibarrola-Jurado N, Bullo M, et al. White blood cell counts as risk markers of developing metabolic syndrome and its components in the Predimed study. PLoS One. 2013;8(3):58354.

3. Clifford GM, Franceschi S. Cancer risk in HIV-infected persons: influence of CD4 (+) count. Future Oncol . 2009;5(5):669-678.

4. George TI. Malignant or benign leukocytosis. Hematology Am Soc Hematol Educ Program. 2012;2012:475-484.

5. Bouwhuis MG, Ten Hagen TL, Eggermont AM. Immunologic functions as prognostic indicators in melanoma. Mol Oncol . 2011;5(2):183-189.

6. Das S, Karim S, Datta Ray C, et al. Peripheral blood lymphocyte subpopulations in patients with cervical cancer. Int J Gynaecol Obstet . 2007;98(2):143-146

7. Gemignani M, Maiman M, Fruchter RG, et al. CD4 lymphocytes in women with invasive and preinvasive cervical neoplasia. Gynecol Oncol. 1995;59(3): 364-369.

8. Spivak M, Lakatosh VP, Lazarenko LM, et al. Interrelation of lymphocyte subpopulations in peripheral blood under cervical papillomavirus infection. Folia Microbiol (Praha) . 1999;44(6):721-725. 
9. Braude S, Beck A. Complete blood counts with differential: more accurate reference ranges based on circadian leukocyte trafficking. $J$ Clin Pathol . 2013;66(11):909-910.

10. Forman D, De Martel C, Lacey CJ, et al. Global burden of human papillomavirus and related diseases. Vaccine. 2012;30(5):12-23.

11. Herrero R, Hildesheim A, Rodriguez AC, et al. Rationale and design of a community-based double-blind randomized clinical trial of an HPV 16 and 18 vaccine in Guanacaste, Costa Rica. Vaccine. 2008;26(37):4795-4808.

12. Hung CF, Wu TC, Monie A, et al. Antigen-specific immunotherapy of cervical and ovarian cancer. Immunol Rev. 2008;222:43-69.
13. Grulich AE, van Leeuwen MT, Falster MO, et al. Incidence of cancers in people with HIV/AIDS compared with immunosuppressed transplant recipients: a meta-analysis. Lancet . 2007;370(9581):59-67.

14. Andrews JM, Cruser DL, Myers JB, et al. Using peripheral smear review, age and absolute lymphocyte count as predictors of abnormal peripheral blood lymphocytoses diagnosed by flow cytometry. Leuk Lymphoma. 2008;49(9):1731-1737.

15. Stanley M, Pinto LA, Trimble C. Human papillomavirus vaccinesimmune responses. Vaccine. 2012;30(5):83-87. 